\title{
Indigenous knowledge systems and early literacy development: An analysis of isiXhosa and isiZulu traditional children's folktales and songs
}

Vuyokazi Nomlomo and Zilungile Sosibo

\begin{abstract}
This paper provides an analysis of IsiXhosa and IsiZulu folktales and traditional children's songs in order to highlight the relationship between Indigenous Knowledge Systems (IKS) and early literacy development in young children. Through the lens of the cognitive and socio-cultural theories, it explores the kind of knowledge embedded in the IsiXhosa and IsiZulu folktales and traditional children's songs, and the value and relevance of such knowledge in supporting early literacy development. It argues that oral literacy in indigenous languages has always existed, but became dormant and invisible as a result of assimilation and acculturation into the Western norms. The paper concludes with an acknowledgement that folktales and traditional children's songs are a rich and perennial reservoir through which young learners can acquire not only literacy skills, but also cognitive, linguistic and social skills that can help them to become active citizens in the world and the workplace.
\end{abstract}

\section{Introduction}

Indigenous Knowledge Systems (IKS) as a field of research has received attention, both internationally and nationally over the past two decades, particularly in Science and Technology (Ogunniyi 1996; Van Wyk 2002; Diwu 2010). IKS research has spread to other fields such as education and African languages, particularly in sub-Saharan Africa (Hoppers 2004; Nyota et al. 2008; Mapara 2009; Gudhlanga et al. 2012; Meyiwa et al. 2013). In South Africa, IKS became part of the curriculum after 1994 in order to acknowledge the history and cultural heritage of the country (Department of Education (DoE) 2002, 2005; Department of Basic Education (DBE) 2012: 5). It was introduced in education as a means of transformation and of accommodating diversity to foster social cohesion and sustainable development (Battiste 2005; Themane et al. 2011). It is acknowledged in the curriculum, particularly in language learning, as a means of providing learners with aesthetic, cultural and imaginative abilities which enable them to understand the world (DoE 2002, 2005; DBE 2012: 8). In this way, IKS is viewed as a powerful tool of identity construction that reflects language and power relations (DoE 2002). 
In this paper, the researchers argue that IKS has always existed (Moropa et al. 1990), but has been invisible in education due to Eurocentric views which perceived it as barbaric and inferior to Western knowledge (Battiste 2005). As a result, school knowledge has been perceived as the only means of education and literacy, while home literacy has been ignored or marginalised. In South Africa, in particular, such practices were perpetuated by the influence of colonial and apartheid rule (Heugh 2003; Prah 2003; Bamgbose 2005). The growing worldwide interest in IKS is a means of reclaiming cultural and traditional values that have been lost through assimilation and acculturation into Western culture, as well as through the values that promote English in many domains of life, including education (Battiste 2005).

This paper focuses on IKS as a knowledge-generating tool that operates in a mediated sociocultural context. IKS highlights cognitive and socio-cultural benefits embedded in folktales and traditional songs which might have been ignored in formal schooling. It ensures that learning is contextualised within local knowledge and oral language. Oral language comprises riddles, rhymes, songs, folktales, proverbs, legends and myths which are of cultural and educational value (Mapara 2009; Meyiwa et al. 2013). In this paper, the researchers analyse IsiXhosa and Isi-Zulu children's folktales and traditional children's songs in order to explore the kind of knowledge they provide to young learners to strengthen their literacy skills. The researchers are motivated by their understanding of IKS as a body of unique local or cultural knowledge which is passed on from generation to generation (Hoppers 2004; Mapara 2009). The researchers are also guided by the social constructivist approach which aligns with the ideological view of literacy as a socio-cultural practice (Street 1984; Bloch 2005), which enables us to understand IKS as a valuable tool in mediating early literacy development.

Another motivating factor is the limited use of folktales and traditional songs at home and at school due to a number of factors such as urbanisation and the influence of television. While some of the folktales feature in a few television programmes, they lack the cultural authenticity as they are driven by market needs. Moreover, many young teachers themselves do not have rich knowledge and understanding of folklore, as some of them have not been adequately exposed to them due to modernisation. Whilst the curriculum prescribes story telling as one of the literacy teaching strategies in early childhood, research shows that most of the stories told to children are Eurocentric (Bloch 1996; Prosper 2012) and incompatible with the socio-cultural experiences of the children that may be embedded in African folktales and traditional songs. It appears that the pedagogic value of utilising folklore is not understood. Therefore, this article attempts to unveil the benefits inherent in using folklore as a pedagogic tool in the classroom, thus acknowledging the pedagogy and significance of teaching IKS in the classroom. As researchers, we intend to share our rich traditional and cultural knowledge in which we were socialised, while contributing to the IKS body of knowledge that might be useful for today's young learners, particularly in literacy development.

Many assessment reports point to a literacy crisis in many South African schools (Howie et al. 2006; DBE 2011; National Education Evaluation and Development Unit (NEEDU) Report 
2012). Low literacy levels are also observed in African languages (Pretorius et al. 2004: 47). The dearth of books written for young children in African languages is also another challenge which impacts on young children's literacy skills (Bloch 1996). As traditional folktales and songs are not written down, they may be imparted to children by word of mouth, and can also be useful to bridge the gap between home and school literacy. In this way, the school can draw on the cultural capital that children bring to school which includes their identities, dispositions, language, memories and other cultural artefacts (Pahl et al. 2005). This paper, therefore, documents local knowledge which is unique to the IsiXhosa and IsiZulu cultures, while providing an insight into cognitive, psychological and educational value of folktales and traditional songs in the development of early literacy. In the following section, more emphasis is on IKS as an epistemology which incorporates cultural traditions and beliefs that are captured in traditional folklore. It highlights the connection between IKS and folklore, and the extent to which folklore could enhance literacy development in young children. It addresses the following research questions:

1. What is the relationship between folklore as part of IKS and early literacy development in IsiXhosa and IsiZulu?

2. What kind of literacy knowledge do children acquire from IsiXhosa IsiZulu folktales and traditional children's songs?

3. How can folktales and traditional songs be used as pedagogical tools to mediate literacy teaching and learning?

\section{Understanding IKS and Early Literacy Development}

Many scholars refer to IKS as a body of knowledge which originated locally and naturally among indigenous people of a particular geographical area/s, and is passed on from generation to generation (Hoppers 2004; Battiste 2005; Mapara 2009). IKS is unique to a given culture (Mapara 2009) and it carries traditional beliefs that are often imparted orally or by example to younger generations, and thus become accepted as cultural system or practices. These beliefs may be about life, death, ancestors, taboos, healing and the role one should play in the family or community (Ogunniyi 1996: 41). It is carried and performed through language, for example, proverbs, riddles, myths, folktales, songs and dance and is reflected in different social dimensions such as agriculture, medicine, craft and skills, judiciary system and social values (Mapara 2009: 153; Gudhlanga et al. 2012: 74). This implies that IKS has its own epistemology, social, educational and ethical relevance (Battiste 2005; Gudhlanga et al. 2012; Meyiwa et al. 2013) which is often embedded in folklore.

Folklore is embedded in IKS in the form of folktales, songs, riddles, myths, proverbs, idioms, etc. It relies on oral literature to explain various socio-cultural phenomena in the environment, and it is a source of entertainment (Akro-Achemfuor 2013). It plays various functions such as mediation of beliefs and decisions, validation of conduct and moral values, expression of emotions and meaning construction (Ntuli 2013; Sivasubramaniam 2013). Folklore carries rich traditional cultural and educational values, but it is not written down due to the fact that events were not documented in African traditional culture, but were transmitted from generation to generation by word of mouth (Akro-Achemfuor 2013; Ntuli 
2013; Moropa et al. 1990). Folklore as part of IKS, therefore, existed as an educational tool before schools were introduced (Ntuli 2013).

During the colonial rule, IKS in education was stigmatised as primitive and inferior, and it became invisible as indigenous people became assimilated into European knowledge (Battiste 2005: 3). In the $20^{\text {th }}$ century, however, IKS scholars began to reclaim and protect the social value and status of indigenous knowledge by acknowledging its role in various sectors of life, such as poverty alleviation, sustainable development and capacity building in many communities (Hoppers 2004; Battiste 2005). Through the lens of the post-colonial theory, they began to challenge the superiority myth of Western knowledge, and promoted the visibility of IKS in education, history, architecture, language and science, thus trying to instil a sense of identity and representation in these various sectors (Ogunniyi 1996; Mapara 2009).

Regarding IKS and language and literacy teaching and learning, young children are exposed to past experiences that they can emulate or avoid, for example respect, problemsolving, good character and a sense of belonging. They are also stimulated to be critical and quick thinkers, with a sense of accountability and responsibility. These skills are inculcated through folklore and the use of proverbs, riddles, folktales and songs which are also educational and entertainment tools (Mapara 2009; Gudhlanga et al. 2012). This suggests that IKS is interdisciplinary and can be associated with the social, cognitive, psychological and economic worldviews (Hoppers 2004).

Educationally, folktales and traditional songs which form part of folklore and IKS are important tools of language and literacy teaching and learning (Ntuli 2013; Sivasubramaniam 2013), Folktales, in particular, form part of story-telling which is an important aspect of literacy development. According to Sivasubramaniam (2013), folktales aroused learners' curiosity and critical thinking, and they are important components of transformative teaching (instead of transmission teaching) which entails collaboration and active participation by learners. They are also powerful expressions of cultural, social and moral values (Sivasubramaniam 2013). As meaning-making narratives, they are chronologically organised in a sequence of events, with a beginning, middle and an end (Elliot 2005). They are characterised by various stages, namely, the abstract, orientation, complicating action, evaluation, resolution and the coda which links past event to the present (Elliot 2005; Feez et al. 1998). In language and literacy learning, these narrative characteristics enable the children to understand the content and form of the folktales, which could be applied in different disciplines.

Folktales are interactive as they involve a performer and an audience who interact in a specific context (Ntuli 2013). They are multi-voice discourses which lay a good foundation for reading, writing, creative thinking, meaning-making and expression of voice which are important literacy elements (Sivasubramaniam 2013). They also instil important values such as appreciation, empathy and understanding as children construct meaning of the stories. In the classroom, these values could be enhanced through discussion, responding to 
reading activities, repetition, analysing the structure of the story, problem-solving, role playing, evaluating and summarising stories (Ntuli 2013; Sivasubramaniam 2013).

In this paper, the researchers explore the nexus between early literacy and IKS as manifested in folktales and traditional songs. The researchers analysed the form and content of selected IsiXhosa and IsiZulu folktales to highlight emerging issues that could be useful in literacy teaching and learning. The researchers are guided by the view of literacy as a socio-cultural practice which is based on belief systems, languages, values and technical skills which reflect one's identity (Pahl et al. 2005). This view of literacy is guided by the New Literacy Studies (NLS) which takes into account the diverse socio-cultural and linguistic contexts of literacy that may not be part of formal schooling (Street 1984; Bloch 2005). In other words, the NLS framework acknowledges the relationship between 'schooled literacy' and other forms of literacy (e.g. community literacy) as a particular form of cultural capital (Baker et al. 2006 in Stein 2008). It acknowledges the fact that literacy is a socio-cultural practice which encompasses other forms of literacy, besides reading and writing only (Street 1984; Street 2005). So, the common thread running between IKS and the New Literacy Studies is the recognition of cognitive structures and the socio-cultural environment in the construction of knowledge.

\section{Theoretical Framework}

In order to understand the nexus between early literacy development and the cognitive and social values of folktales and traditional songs, the researchers draw on social constructivism which is an interconnection between Piaget's (1973) cognitive theory and Vygotsky (1987) sociocultural theory (Palincsar 1998). Social constructivism emphasizes the significance of the home language and experiential knowledge in learning. It believes that knowledge develops as one engages in dialogue or interacts with others (Palincsar 1998). It views knowledge as a developmental, cultural and socially mediated process which involves interaction between the most knowledgeable others (MKOs) and the less experienced (Yilmaz 2008). According to social constructivists, an enabling and interactive environment is very crucial in constructing new knowledge (Yilmaz 2008; Ohta 2000; Bruning et al. 1999).

With regard to teaching and learning, social constructivism encourages the recognition of learners' prior knowledge as a significant resource in mediating knowledge construction (Ohta 2000). Concerning literacy teaching, social constructivism values the variety of literacies acquired by children from the surrounding environment through informal interactions such as talks, play, folklore, etc. which occur mainly through the children's first languages (Street 1995). It views such knowledge as a good foundation for other literacy events and practices including listening, reading, writing, imagination and meaning-making of the learning content. In the performance or narration of folktales, learners cross the border from informal (home) literacy to formal (school) literacy as they construct their own meaning from the stories. In this way, they construct literacy knowledge which is significant in their learning across the curriculum. In this paper, the researchers view social constructivism as an appropriate lens to understand how children construct knowledge from folktales and traditional songs. The researchers believe that young children depend on the cognitive or 
mental structures and the social environment to construct literacy knowledge. The cognitive structures include higher order thinking tools to stimulate critical and problem solving skills (Kozulin 1998), while the sociocultural environment encourages information sharing and interaction between individuals who learn from each other. As literacy is regarded as both a cognitive and socio-cultural practice (Baynham 1995), the researchers argue that folktales and traditional songs have epistemology which is influenced by a number of factors such as language proficiency and pedagogical strategies employed in literacy lessons. This implies that literacy teaching strategies should encourage learners' active engagement in the form of individual and collaborative activities which may include guided, paired and shared reading and writing (DBE 2011). Thus the researchers made an attempt to understand how folktales and traditional songs as part of IKS can be used as pedagogical resources to enhance children's literacy skills such as listening, speaking, reading, writing, imagination and comprehension by employing a narrative analysis which they discuss below.

\section{Methodological and analytical framework}

This paper employed a narrative analysis to unpack the content and form of selected IsiXhosa and IsiZulu folktales. Narrative analysis forms part of the qualitative approach to data collection. It is relevant to research which is underpinned by social constructivism epistemology. Narrative analysis views data as useful information which is socially constructed (Henning et al. 2004), and has been used in many sociolinguistics and literary studies to examine the different functions of language in terms of meaning, structure and interactional context (Elliot 2005). Given this, narrative analysis is both a linguistic and interpretive methodology, and an analytical tool that interrogates socially constructed knowledge in social interaction and communication. Socially constructed knowledge may depict personal values, feelings, attitudes imagination of the participants. In qualitative research, narrative analysis serves as a method to capture past or historical experiences by matching verbal sequence to the sequence of events (Elliot 2005).

In this paper, the researchers focused on the analysis of IsiXhosa and IsiZulu folktales in order to understand how they reflect literacy components that can enhance young learners' early literacy skills. As folktales and traditional songs are part of oral literature (Moropa et al. 1990), the researchers relied on their own experiences and how they were socialized in the folktale epistemology in and out of school. They selected common folktales and songs in IsiXhosa and IsiZulu which are still relevant and applicable in today's classroom with regard to literacy and numeracy teaching and learning in early schooling. The researchers examined both the form and content of the selected folktales and songs in order to identify their linguistic elements and meaning in relation to isiXhosa and isiZulu cultural values and norms, as well as the extent to which they enhance children's literacy development. In line with social constructivism, the researchers took into account the form of interaction and the instructional role of the "more knowledgeable other", in order to understand how literacy is mediated through the use of folktales and traditional songs. Overall, narrative analysis enabled their to make sense of isiXhosa and isiZulu folktales and traditional songs, and their relevance to early literacy teaching and learning. 


\section{Results and discussion}

From the analysis of the selected isiXhosa and isiZulu folktales and traditional songs, the researchers deduced that there were common elements that pertained to literacy instruction, namely, the development of literacy and oral skills, the content and role of folktales in literacy development and how folktales facilitate children's knowledge construction and their access to integrated knowledge. In other words, the indigenous knowledge embedded in folktales and songs as part of IKS is imparted and mediated through listening and speaking, in a dialogical manner. Another observation was that through the use of folktales, learners get exposed to different types of texts and knowledge which are relevant to different disciplines such as mathematics or numeracy. In other words, folktales and songs provide learners with integrated knowledge forms. Below the researchers discuss at length each of these above stated observations.

\section{Listening and Oral Literacy Skills through Dialogical Interaction}

In this analysis, the researchers observed that folktales strengthen learners' listening and oral skills. In both the IsiXhosa and IsiZulu folktales the narrator stimulates children to listen, and collaborate with the narrator during story-telling. The analysis indicates that folktales are a performance which is derived from individual creativity and pedagogical skills, irrespective of formal educational levels. In other words, they impart indigenous knowledge which is relevant in today's context. The story is narrated in a sequential and organised manner that demands children's attention and creativity to make connections between what they already know (pri- or knowledge) and the new knowledge. As there is a speaker (or narrator) and a listener, this kind of interaction stimulates young learners' listening skills and imagination which are crucial in literacy development. When the narrator (old person) starts speaking, s/he demands attention and discipline from the listeners (children), who have to commit themselves that they will be cooperative and quiet while the narrator speaks. For example, in the isiXhosa folktale entitled Umsila wembulu (The rabbit's tail), the narrator starts off by commanding attention, as a way of introducing the folktale:

NARRATOR: Kwathi ke kaloku ngantsomi

(Here comes the folktale/story)

LISTENERS: Chosi ntsomi! (We are ready

for the folktale/You can start/We are listening)

In IsiZulu, the narrator will start in this way:

NARRATOR: Kwasukasukela (Once upon a time)

LISTENER: Cosi (We are ready to listen)

In line with the social constructivist view (Palinscar 2008), the above interaction is dialogical between the narrator (who could be a parent or teacher) and the listeners. In pedagogical terms, the narrator has an orientation or introduction that facilitates a dialogue between the narrator and the listeners. According to Martin et al. (2007), this stage of talk is crucial in literacy teaching as the experienced person (for example parent or teacher) initiates an interaction to prepare the young learners for the lesson. A dialogical approach facilitates active learning and critical thinking (Gibbons 2002). In this case, it 
stimulates learners' listening and speaking skills by challenging them to pay attention to the story and to indicate that they are ready to listen by responding thus: "Chosi ntsomi or Cosi" as shown above. In literacy teaching, it is important to grant children opportunities to listen and speak as the two language skills are important in literacy development. They form the basis for emergent reading and writing (Bloch 1996).

Listening exposes learners to new vocabulary which forms the foundation of other literacy skills such as reading and writing. For example, the concept of "Chosi/Cosi" is uncommon in everyday communication as it is associated with traditional healers when they communicate with their patients. In has the same meaning in both the folktale and traditional healing contexts as it symbolizes commitment or cooperation with the speaker, which, in simple terms, would be "Simamele/Silalele - We are listening/We are ready." In this case, young children get an opportunity to learn and assimilate new ways of using one term in different contexts. Such an approach is likely to enhance their understanding and use of certain concepts in varying contexts: thus increasing their vocabulary. This finding aligns with the view that vocabulary development is a cognitive process and it supports learners to construct meaning of what they learn (Apthorp 2006; Biemiller et al. 2006; Harmon et al. 2010). Therefore, this finding suggests that folktales as part of IKS, play a significant role in the cognitive development of young children (Nyota et al. 2008). They also serve as a means of entertainment as suggested by Ntuli (2013) and Moropa et al. (1990). These finding align with the requirements of CAPS which reading for enjoyment or entertainment (DBE 2012).

Although vocabulary is not considered a writing convention, it is an important aspect contributing to good writing. It is believed that learners who receive vocabulary instruction that engages them in playful activities using a range of words in rhythms and songs often have more words when it comes to writing (Gambrell et al. 2007: 245). Such learners usually produce different texts of higher quality than learners who do not receive such instruction. This is to suggest that vocabulary development is not only an index of intelligence but also an index of literacy. During the vocabulary building lessons in multilingual classrooms, learners need to have access to bi/multilingual dictionaries where they can be encouraged to select words and look for appropriate words to use in their writing. The words of their choice may also be used in creating their own definitions, as well as sentences for each word. In doing so, the teacher encourages the development of multilingual literacies whereby learners acquire skills from different languages.

Narrative analysis also showed that the two African languages have culturally rooted epistemology which instils the community's social beliefs and norms such as obedience and respect as attested by Gudhlanga et al. (2012). The social value of the dialogic interaction between the narrator and listeners is that when an elderly person speaks, learners learn have to pay attention and respect while the speaker is on the floor. They can only talk when offered a turn by the speaker. This is a way of maintaining order and discipline in the learning environment, while teaching young learners to respect each other, and to wait their turns in whatever they do. This kind of interaction can be associated with turn-taking which has to do 
with how turns are allocated and received in a talk or conversation (Hutchby et al. 2008). It is a pedagogical strategy which takes into consideration what kind of knowledge to be exchanged and how it has to be transmitted (Nomlomo 2010). In the analysis of isiXhosa and isiZulu folktales turn-taking appears to be relevant as the narrator initiates or allocates a turn to the listeners. For example, Kwathi ke kaloku ngantsomi/Kwasukasukela Here comes the folktale), who accept their turn by responding in "Chosi/Cosi". As indicated earlier, literacy entails the acquisition of listening, reading, oral and comprehension skills which tend to be reinforced in turn-taking and allocation. Moreover, literacy as a sociocultural practice incorporates cultural values and norms that may transmitted across generations (Ntuli 2013; Moropa et al. 1990). So the social values do not form part of literacy instruction only, but they may be applicable in all spheres of life, including formal education and the workplace.

\section{The Content and Role of Folktales in Literacy Development}

The new language curriculum referred to as Curriculum Assessment Policy Statement (CAPS) proposes communicative and text-based approaches to literacy teaching (DBE 2012). Therefore, it is necessary that learners from early schooling onwards are exposed to different types of text that form a foundation of learning in other learning areas (for example history, science). Folklore, which comprises folktales or narratives, rhymes and songs, is prescribed in the Foundation Phase (Grades $\mathrm{R}-3$ ) language curriculum (DoE 2005; DBE 2011). Narratives influence people's behaviour and the way they understand the world (Feez et al. 1998).

Interestingly, the structure of the traditional folktale corresponds with the conventional or modern narrative which comprises different stages, namely, orientation, complication and evaluation (Elliot 2005; Feez et al. 1998). Firstly, there is an introduction or orientation phase which gives characters, place and time (plot) in order to induct the learners to the main story. In the orientation phase, the listeners are introduced to the problem/s that might cause conflict among characters (Elliot 2005; Feez et al. 1998). In the complication stage, the listeners discover the problem on their own, while the evaluation stage creates suspense and the listeners are challenged to find out what happens next (Feez et al. 1998). All these stages enhance literacy instruction as they reinforce not only children's listening skills, but also their comprehension and imagination which are key components of literacy development.

In the analysis of "Umsila wembulu" (IsiX- hosa folktale), the narrator refers to characters like the chief and animals (domestic and wild) in the orientation phase. The learners are also told about the time (kudala-dala/long ago, ngonyezi/ early morning), place (ihlathi/the forest) where the events took place and the possible conflict that could arise (for example rabbit's defiance to the chief's call).

NARRATOR: Kudala-dala, kwakukho izilwanyana. Ezi zilwanyana zazihlala ehlathini elinye neNkosi yazo. INkosi yayixakanisekile kukuba izilwanyana zasemakhaya zona zinemisila, 
yaze yabiza intlanganiso yezilwanyana ukuze zibonisane ngale ngxaki. Zavuka kwangonyezi zonke izilwanyana, zileqa intlanganiso, ngaphandle kwembila eyashiyeka yothe ilanga yona.

Long, long time ago, there were animals. These animals lived in the forest with their Chief. The chief was concerned that the domestic animals had tails, and he convened a meeting for all the wild animals. All the animals woke up very early to attend the meeting, except the rabbit which was left basking in the sun.

In this folktale, as the monkey took the rabbit's tail to itself, the complication stage is reached. According to Feez et al. (1998) the complication is the heart or centre of a narrative. Educationally, this stage provokes learners' critical thinking and suspense as they have to question what happens next.

Yayaleza inkawu ukuba ize iyikhethele umsila. Inkawu yawuthatha umsila wembulu, yawuxomezelela kowayo, yatsho yanogqajolo lomsila yona.

It delegated the monkey to choose a tail on its behalf. The monkey took the rabbit's tail and extended its own. Hence it is having a very long tail.

The evaluation stage challenges the learners to discover the significance of the story as they try to make connections between explicit and implicit knowledge. In this way, they construct meaning as they evaluate the situation in relation to their prior knowledge, beliefs and attitudes shaped by their socio-cultural environment. In the present story, the learners are educated and cautioned about the consequences of laziness or lack of compliance. They are also scaffolded to higher levels of linguistic competence as the folktale could be translated into an IsiXhosa proverb that "Imbulu yaswel'umsila ngokuyalezela / A rabbit sacrificed its tail because of delegation". This implies that apart from the social values and beliefs embedded in traditional folktales, they are also good communicative, educational and ethical tools (Battiste 2005; Meyiwa et al. 2013).

An IsiZulu folktale that follows a similar pattern is narrated below. In the analysis of "uMpisi noNogwaja" (the Hyena and the Hare), the narrator refers to characters like the hyena and the hare (both wild animals) that are personified in the orientation phase. The learners are also told about the time (emandulo/long ago), place (ihlathi/the forest) where the events took place and the possible conflict that could arise as a result of the different characteristics of these animals (for example cunning hyena, wise hare).

NARRATOR: Emandulo kwakukhona izilwane ezazihlala ndawonye ehlathini elikhulu. Phakathi kwazo kwakukhona uMpisi owayese kabi owayehlala eduze kukaNogwaja owayehlakaniphe kabi. Ngelinye ilanga uMpisi wazizwa elambile wase eza neqhinga lokudla uNogwaja. Wase eya kwaNogwaja wacela ukuthi badlale umdlalo wokuphekaphekana. Wavuma uNogwaja. Wabaswa umlilo. Kwafuneka kube khona oqalayo. UNogwaja wathi uzongena kuqala. Wanele ukungena uMpisi wabasa kakhulu. Emva kwesikhashana 
wamemeza uNogwaja ukuthi sekufanele bashintshane kungene uMpisi. Nangempela waphuma uNogwaja kwangena uMpisi.

Long, long ago there were animals that lived together in a big forest. Among them was a cunning hyena that lived nearby a wise hare. One day the hyena was very hungry. He decided that it would be good to eat the hare. So he came up with a plan. He went to the hare and asked him/her to play the cooking game. The hare said it is fine. After making a big fire, it was time to decide who would get into the pot first. The hare offered to go first. After getting into the pot, the hyena made the fire even bigger. After a little while the hare screamed that it was the hyena's turn to get into the pot. The hyena agreed but this time the water in the pot was already hot.

The complication stage was reached when the hyena got into the pot and the hare made the fire bigger and bigger. The listeners are kept in suspense, wondering what is going to happen

next.

Wawubasa wabomvu umlilo uNogwaja. Emva kwesikhashana wakhala uMpisi wathi sekufanele kungene uNogwaja kodwa wala waphetha uNogwaja wathi asikaneli isikhathi esingenwe nguMpisi ebhodweni. Waqinisela uMpisi wabasa uNogwaja kwaya ngokuya kuba kukhulu ukukhala kukaMpisi. Emva kwesikhathi kwaphela ukukhala kukaMpisi kanti usifile.

The hare made the fire bigger and bigger. After a little while the hyena screamed for the hare to take his/her turn but the hare replied that it was not yet time for the hyena to get out. The more the water in the pot got hotter, the louder and louder the hyena's creams became. After a while there were no screams anymore coming from the pot, as the hyena had died.

As in the IsiXhosa folktale, in the IsiZulu tale the evaluation stage challenges the learners to discover the significance of the story and to make meaning. In the latter story, the learners are taught about the consequences of being cunning. They are also scaffolded to higher levels of linguistic competence as the folktale could be translated into IsiZulu proverb that "Akukho qili lazikhotha emhlane / No matter how cunning you are, you cannot lick your own back". This simply means that even if you think you are clever, there will come a time when it will catch up with you.

The stage of resolution is where the problem is solved. The narrative is usually rounded off in a short comment. For example, in IsiXhosa the narrator ends in this way: "Phela phela ngantsomi/End of the story". In IsiZulu, the ending is: "Cosi cosi yaphela/End of the story." In both cases, the researchers observe the narrators' creativity of putting events in a time or chronological sequence. The same principle is followed in conventional and eurocentric narratives (Feez et al. 1998). Therefore, it can be argued that modern learning is an 
extension of indigenous knowledge, although the latter is not explicitly acknowledged in formal schooling.

\section{Integrated Knowledge and Literacy Development}

In the IsiXhosa folktale presented above, the learners are exposed to their socio-cultural environment. They are taught about the importance of traditional community gatherings as spaces where big decisions are taken by the "chief" or anyone in possession of power. They can relate to such meetings as community members. In the IsiZulu folktale they learn about living together in a community of others, which they are familiar with as they grow up surrounded by communities of neighbours. Cognitively, they are challenged to think and use their imagination skills, as the animals are personified; they can talk and act like human beings. The learners are also exposed to the natural environment, that is the world of animals which portrays the structure and behaviour of each animal. For example, the rabbit is lazy, while the monkey is portrayed as a clever and active animal. Similarly, the hyena is cunning while the hare is wise. The social value of the IsiXhosa story is that people must not expect others to work for them; they must be proactive and work hard to earn the benefits. In a similar vein, the IsiZulu folktale has a moral lesson and social value in that it teaches children not to undermine others' intelligence. These are lessons and life skills that are relevant to human life. In other words, the folktales develop the character of children as responsible adults who should participate actively as community members (Gudhlanga et al. 2012).

Traditional songs also play a role in socialising children in their cultural environment. They support the learners' communicative, cognitive and social abilities through language (Nyota et al. 2012). For example, the following IsiXhosa traditional song exposes the learners to mathematical or numeracy skills in the form of counting. This song, in particular, teaches the learners subtraction from five to zero. It also reinforces the learners' understanding of counting and the natural environment as it refers to pigeons and trees. In the African culture, pigeons are regarded as the most prestigious birds that are associated with beauty. In this context, the learners' aesthetic skills are stimulated as part of literacy learning in the modern curriculum. This indicates that literacy learning integrates different forms of knowledge from various disciplines like mathematics, natural studies, lifeskills and cultural studies. 
Amahotyazana mahlanu There are five pigeons

emthini,

on the tree,

Kwabhabha lalinye, One flew away, and four

kwasal'amane.

are left.

Amahotyazana mane emthini,

There are four pigeons on

the tree,

Kwabhabha lalinye, kwasal'amathathu.

Amahotyazana

mathathu emthini,

Kwabhabha lalinye,

kwasal'amabini.

Amahotyazana mabini

emthini,

One flew away, and three are

left.

There are three pigeons on

the tree,

One flew away, and two are

left.

There are two pigeons on

the tree,

Kwabhabha lalinye, kwasala lalinye.

Ihotyazana linye

emthini,

Kwabhabha lalinye,

akwasal'anto.

One flew away, and one is left.

There is one pigeon on the tree,

One flew away, and nothing

is left.

The above discussion suggests that folktales and songs are linguistic and cultural resources which learners bring to the classroom as a form of home or community literacy (that is indigenous knowledge). According to Street (1995), home literacy can be referred to as alternative literacies that children learn from home as part of indigenous knowledge (Prosper 2012). Alternative literacies challenge the dominance of formal or school literacy, while they support the teaching and learning of literacy (Street 1995). They support the view that learners' prior knowledge and experiences from their immediate environment are an important foundation for the acquisition of formal literacy. This corresponds with the NLS framework, which embraces the integration of schooled literacy and home or community literacy (Baker et al. 2006 in Stein 2008), as discussed earlier. This illustrates that the knowledge taught in schools is shaped by the local context that depicts social identity (Nyota et al. 2008; Meyiwa et al. 2013). Therefore, the learners' socio-cultural experiences provide rich indigenous knowledge which can be integrated in the teaching and learning of literacy to young children (Prosper 2012).

\section{Conclusion}

In this paper, the researchers have shown that indigenous knowledge, which is often marginalised in formal learning, is central to early literacy development as young learners are exposed to oral language in their natural or social environments. In other words, there is a relationship between IKS and early literacy development in IsiXhosa and IsiZulu. While the researchers acknowledge other means of early literacy development such as games, rhymes and dance, the analysis of folktales and children's songs shows that listening and 
oral or speaking skills are interrelated and learned together. The paper also shows that folktales (or narratives) and traditional children's songs are a rich reservoir for empowering learners with different kinds of knowledge, such as social and ethical values. The kinds of knowledge are shaped by the learners' socio-cultural environment and they reflect the children's social identity. In other words, folktales and traditional children's songs are not only indigenous forms of knowledge that enhance learners' cognitive, linguistic and social skills, but are also valuable pedagogical tools in literacy instruction. The values and skills acquired from folktales and traditional songs are relevant in the workplace, and they prepare the children for adult life.

\section{Recommendations}

As indicated in this discussion and in the work of other scholars, folktales and songs lay a good foundation for early literacy development in African languages. Through their interactive and dialogical roles, they stimulate the learners' imagination and cognition, as well as their oral skills which are fundamental for literacy development. Therefore, it is imperative that they are explicitly stated or visible in the national language curriculum as part of literacy instruction and learning.

The revitalization of indigenous knowledge as part of the school curriculum could be instilled in Teacher Education programmes by incorporating traditional literature and literacy as part of the curriculum. The participation of parents as narrators of indigenous folktales in African languages can benefit both the teachers and learners, whilst strengthening their involvement in the education of their children. Therefore, research projects in this subject should collaborate with parents as valuable participants with experience and abilities in mediating literacy teaching and learning through indigenous folktales which are gradually dying out.

Finally, there is limited empirical research on the integration of IKS in literacy teaching and learning, particularly in the early years of schooling. The researchers recommend that attention be paid to the intersection between folktales and IKS as part of home and school literacy. Given the literacy crisis in many South African schools, particularly in the Foundation Phase (Grades $\mathrm{R}-3$ ), there is a need for fresh empirical research on how to utilize folktales in indigenous African languages as socio-cultural and linguistic resources in literacy teaching and learning. 


\section{References}

Akro-Ahemfuor A 2013. Teaching moral values to youth through Anase Stories among the Akan in Ghana. Southern African Journal for Folklore Stud-ies, 23(1): 74-85.

Apthorp HS 2006. Effects of a supplemental vocabu- lary program in third-grade reading/language arts. The Journal of Educational Research, 100: 67-79. Bamgbose A 2005. Mother tongue education: Lessons learnt from the Yoruba experience. In: B Brock- Utne, RK Hopson (Eds.): Languages of Instruction for Emancipation: Focus on Postcolonial Contexts and Considerations. Dar es Salaam: Mkuki na Nyota Publishers, pp. 231-255.

Battiste M 2005. Indigenous knowledge: Foundations for first nations. World Indigenous Nations Higher Education Consortium (WINHEC) Journal, (2): 192-208. Baynham M 1995. Literacy Practices: Investigating Literacy in Social Context. London, New York: Longman Group Limited.

Biemiller A, Boote C 2006. An effective method for building meaning vocabulary in primary grades. Journal of Educational Psychology, 98: 44.

Bloch C 1996. Literacy in the Early Years: Teaching and Learning in Multilingual Early Childhood Classrooms. PRAESA Occasional Papers, 6. Cape Town: University of Cape Town.

Bloch C 2005. Enabling Effective Literacy Learning in Multilingual South African Early Childhood Classrooms. PRAESA Occasional Papers, 16. Cape Town: University of Cape Town.

Department of Basic Education (DBE) 2011. National Curriculum Statement Grade R-12 Curriculum and Assessment Policy Statement (CAPS). Pretoria: Department of Education.

Department of Basic Education (DBE) 2012. Report on the Annual National Assessment of 2011. Pretoria: Department of Education.

Department of Education (DoE) 2002. Revised National Curriculum Statement Grades $R-3$ (Schools) Foundation Phase. Pretoria: Department of Education.

Department of Education (DoE) 2005. National Curriculum Statement Grades $R-3$ (Schools) Languages-English Home Languages. Pretoria: Department of Education.

Diwu Christopher 2010. Effects of a Dialogical Argumentation Instruction Model on Grade 10 Learn- ers' Conceptions of Fermentation. MEd Thesis, Unpublished. Cape Town: University of the Western Cape.

Elliot J 2005. Using Narrative in Social Research. London: SAGE Publications.

Feez S, Joyce H 1998. Writing Skills: Narrative \& Non- Fiction Text Types. Australia: Phoenix Education Pty Ltd.

Gibbons $\mathrm{P}$ 2002. Scaffolding Language, Scaffolding Learning: Teaching Second Language Learners in the Mainstream Classroom. Portsmouth: Heinemann.

Gudhlanga ES, Makaudze G 2012. Indigenous knowledge systems: Confirming a legacy of civilisation and culture on the African continent. Prime Jour-nal of Social Sciences, 1: 72-77. 
Harmon J, Buckelew-Martin E, Wood KD 2010. The cognitive approach to word learning. The English Journal, 100: 100-107.

Henning E van Rensburg W, Smit B 2004. Finding your way in Qualitative Research. Pretoria: Van Schaik Publishers

Heugh K 2003. Language Policy and Democracy in South Africa. PhD Thesis, Published. Sweden: Uni- versity of Stockholm.

Hoppers OCA 2004. Culture, Indigenous Knowledge and Development: The Role of the University. Oc- casional Paper No. 5. Braamfontein: Centre for Education Policy Development.

Howie S, Venter E, van Staden S, Zimmerman L, Long C et al. 2006. Progress in International Reading Liter- acy Study. South African Children's Reading Literacy Achievement. Pretoria: University of Pretoria. Hutchby

I, Wooffit R 2008. Conversation Analysis. $2^{\text {nd }}$ Edition. Cambridge: Polity Press.

Kozulin A 1998. Psychological Tools: A Socio-cultural Approach to Education. United States of America: Library of Cataloging-in-Publication Data.

Lantolft JP, Thorne SL 2006. Socio-cultural Theory and the Genesis of Second Language Development. New York: Oxford University Press.

Mapara J 2009. Indigenous knowledge systems in Zimbabwe: Juxtapositioning postcolonial theory. The Journal of Pan African Studies, 3: 139-155.

Martin JR, Rose D 2007. Interacting with the Text: The Role of Dialogue in Learning to Read and Write. Foreign Studies Journal, Beijing. From <http://www.readingtolearn.com.au/images/pdf/Interacting_ with_Text.pdf> (Retrieved on 10 October 2014).

Meyiwa T, Letsekha T, Wiebesiek L 2013. Masiham- bisane, lessons learnt using participatory indigenous knowledge research approaches in a school based collaborative project of the Eastern Cape. South African Journal of Education, 4: $1-15$.

Moropa CK, Tyatyeka DM 1990. Kusadliwa Ngendeb'Endala (When People Lived According to their Traditional Culture and Customs). Umtata: Shuter \& Shooter.

National Education Evaluation and Development Unit (NEEDU) 2012. Report on the State of Literacy Teaching and Learning in the Foundation Phase. Pretoria: NEEDU.

Nomlomo V 2010. Classroom Interaction: Turn-taking as a pedagogical strategy. Per Linguam, 26(2): 50-66.

Ntuli CD 2013. Folktale performance: An oral art that teaches children. Southern African Journal for Folklore Studies, 23(1): 86-105.

Nyota S, Mapara J 2008. Shona traditional children's games and play: Songs as indigenous ways of knowing. The Journal of Pan African Studies, 2: 189- 202.

Ogunniyi MB 1996. Effects of Science and Technology on Traditional Beliefs and Cultures. Promoting Public Understanding of Science and Technology in Southern Africa. Proceedings of a Southern African Conference at the University of the Western Cape, 4-7 December.

Pahl K, Rowsell R 2005. Literacy and Education:Understanding the New Literacy Studies in the Classroom. London: Paul Chapman. 
Palincsar SA 1998. Social constructivist perspective on teaching and learning. Annual Rev, 49: 345-375.

Piaget J 1973. The Child and Reality: Problems of Genetic Ppsychology. Oxford, England: Grossman.

Prah KK 2003. Going native: Language of instruction for education, development and African emancipation. In: B Brock-Utne, Z Desai, M Qorro (Eds.): Language of Instruction in Tanzania and South Africa (LOITASA). Dar-es-Salaam: E \& D Limited.

Pretorius EJ, Machet MP 2004. Literacy and disadvantage: Learners' achievements in the early pri- mary school years. Africa Review of Education, 1: 128-146.

Prosper A 2012. What do Grade 1 Learners Write? A Study of Literacy Development at a Multilingual Primary School in the Western Cape. MEd Thesis, Unpublished. Cape Town: University of the West- ern Cape.

Sivasubramaniam S 2013. Folktales in Language Class- rooms. Southern African Journal for Folklore Studies, 23(1): 62-73.

Stein P 2008. Multimodal Pedagogies in Diverse Classrooms: Representation, Rights and Resources. Lon- don and New York: Routledge.

Street B 1984. Literacy in Theory and Practice. Cam- bridge: Cambridge University Press.

Street B 1995. Social Literacies. London: Longman. Street B 2005. Literacies across Educational Contexts: Mediating Learning and Teaching. Philadelphia: Caslon Publishing.

Themane MJ, Mamabolo JM 2011. Diversity as a Cur- riculum Challenge in South African Schools. From <http://www.saqa.org.za/docs/promo/2011/themane. pdf > (Retrieved 4 October 2014).

Turuk MC 2008. The relevance and implications of Vygotsky's sociocultural theory in the second lan- guage classroom: ARECLS, 5: 244-262.

Van Wyk JA 2002. Indigenous knowledge systems: Im- plications for natural science and technology teaching and learning. South African Journal of Educa- tion, 22: 305312.

Vygotsky LS 1987. The Collected Works of L.S. Vy-gotsky. New York: Plenum.

Yilmaz K 2008. Constructivism: Its theoretical under- pinnings, variations, and implications for classroom instruction. Educational Horizons, 86: 161-172. 